\title{
The Role of HER2/neu Overexpression/Amplification in the Progression of Ductal Carcinoma In Situ to Invasive Carcinoma of the Breast
}

\author{
E. K. Latta, M.D., S. Tjan, M.L.T., R. K. Parkes, M.Sc., F. P. O’Malley, M.B. \\ Department of Pathology and Laboratory Medicine, Mount Sinai Hospital (EKL, ST, FPO'M), Toronto, \\ Canada; Division of Epidemiology and Biostatistics, Samuel Lunenfeld Research Institute (RKP), Toronto, \\ Canada; Department of Laboratory Medicine and Pathobiology, University of Toronto (EKL, FPO'M), \\ Toronto, Canada
}

HER2/neu overexpression/amplification is seen more frequently in ductal carcinoma in situ, particularly high-grade ductal carcinoma in situ (50-60\%), than in invasive ductal carcinoma of the breast (25-30\%). To date, however, the role of HER2/neu in the progression of in situ to invasive disease has not been clarified. Two hundred fiftyone breast tumors were retrieved from the pathology files at Mount Sinai Hospital. These included 91 cases of ductal carcinoma in situ, 136 cases of invasive ductal carcinomas with associated ductal carcinoma in situ, and 24 cases of pure invasive carcinomas. All cases were reviewed and stained with two monoclonal antibodies to HER2/neu (CB11 and TAB250). Immunohistochemical staining was recorded using a semiquantitative scoring system (1). Representative cases were also investigated using fluorescence in situ hybridization. HER2/neu protein overexpression (defined as immunohistochemical staining with score of $\geq 5$ ) was seen in $34 \%$ of cases of pure ductal carcinoma in situ, $17 \%$ of invasive carcinomas with associated ductal carcinoma in situ, and $12.5 \%$ of pure invasive carcinomas $(P=$ $.01)$. Sixty percent of cases of high-grade ductal carcinoma in situ showed HER2/neu protein overexpression, versus $29 \%$ of high-grade invasive carcinomas with associated ductal carcinoma in situ and $\mathbf{2 2 \%}$ of high-grade pure invasive ductal carcinomas $(P=.02)$. The concordance between the immunohistochemical staining in the in situ and invasive components of individual tumors was $\mathbf{9 0 \%}$. Thirtythree cases were also evaluated by fluorescence in

Copyright $(\odot 2002$ by The United States and Canadian Academy of Pathology, Inc.

VOL. 15, NO. 12, P. 1318, 2002 Printed in the U.S.A.

Date of acceptance: September 3, 2002.

Address reprint requests to: Frances P. O’Malley, M.B., Dept. of Pathology and Laboratory Medicine, Mount Sinai Hospital, 600 University Avenue, Toronto, Canada M5G 1X5; e-mail: fomalley@mtsinai.on.ca.

DOI: 10.1097/01.MP.0000038462.62634.B1 situ hybridization and showed concordance between the immunohistochemical results and the degree of gene amplification in $91 \%$ of cases, whereas 3 of 33 cases showed HER2/neu gene amplification (HER2/CEP17 $=$ 2.3-3.7) by fluorescence in situ hybridization in the absence of positive immunohistochemical staining. One case showed HER2/neu gene amplification in the associated ductal carcinoma in situ (HER2/CEP17 ratio $=6.5$ ), with no evidence of gene amplification in the invasive tumor $($ HER2/CEP17 ratio $=1.14)$. Multiple genetic events are required for the development of an invasive phenotype. The findings from this study suggest that the genetic event of HER2/neu gene amplification/protein overexpression may not play a key role in the progression of ductal carcinoma in situ to invasive carcinoma and that other molecular alterations may be more important in the initiation of invasion in ductal carcinoma of the breast.

KEY WORDS: Ductal carcinoma in situ, HER2/neu, HER2/neu gene amplification, Immunohistochemistry, Invasive breast carcinoma.

Mod Pathol 2002;15(12):1318-1325

The importance of HER2/neu in cancer has been a topic of considerable interest of late, both in its role as a prognostic indicator and as a predictor of response to therapy (2-8). With the advent of the drug Herceptin, assessment of HER2/neu status in patients with metastatic breast carcinoma has become an even more important clinical consideration.

Previous studies have shown that approximately $25-30 \%$ of invasive ductal carcinomas of breast show HER2/neu overexpression/amplification (9). In contrast, the incidence of HER2/neu overexpression/amplification in ductal carcinoma in situ is $\geq 60 \%$ (10-12), whereas benign and atypical breast lesions generally do not show any evidence of HER2/neu overexpression (13). To date, there have 
been few data concerning HER2/neu overexpression/amplification in invasive breast carcinomas that also have an associated in situ component. If HER2/neu overexpression is a key factor in the initiation of invasion, then the rate of HER2/neu overexpression/amplification in this group of tumors could be expected to show a rate of overexpression similar to that seen in pure ductal carcinoma in situ.

In this study we assessed HER2/neu overexpression/amplification in a group of invasive tumors with associated ductal carcinoma in situ and compared the results to those seen in cases of pure ductal carcinoma in situ and pure invasive carcinomas to determine whether HER2/neu overexpression/amplification played a role in the progression of ductal carcinoma in situ to invasive ductal carcinoma of the breast.

\section{METHODS}

From the archives of the Department of Pathology at Mount Sinai Hospital, 298 consecutive cases of pure invasive ductal carcinoma and invasive tumors with associated in situ disease were identified and retrieved, dating between January 1998 and November 1999. In addition, 219 consecutive cases of ductal carcinoma in situ, dating from April 1996 to November 1999, were also retrieved. Of these 517 cases, 171 (62/219 and 109/298) were core needle biopsies and were excluded. A further 22 cases (11/ 219 and 11/298) were repeat excisions from patients already included in the study, and these were also excluded. In each case where multiple resections had been performed on a patient, the definitive resection (lumpectomy, mastectomy, etc.) was used for evaluation in this study. Of the remaining 146 cases of ductal carcinoma in situ, 52 were excluded for various other reasons, including lack of sufficient tissue for immunohistochemical evaluation or unavailability of tumor blocks. Of the 178 pure invasive ductal carcinomas and invasive carcinomas with associated ductal carcinoma in situ from January 1998 to November 1999, 18 were excluded for similar reasons as those described above, giving a total of 160 cases. These cases, combined with the 94 cases of ductal carcinoma in situ, were included in this study. Because of technical problems with the immunohistochemical staining procedures, results could not be obtained for 3 cases of ductal carcinoma in situ, giving a final total of 251 cases.

Demographic information, including age of the patient, type of resection, and estrogen and progesterone receptor status was obtained from the case files and is shown in Table 1 . All of the invasive carcinomas were reviewed and graded using El- ston's modification of the Bloom-Richardson grading system (14). The nuclear grade was recorded for the cases of pure ductal carcinoma in situ as well as for the ductal carcinoma in situ associated with cases of invasive carcinomas. For each case, a representative paraffin block containing tumor was chosen, and sections were taken for HER2/neu immunohistochemistry and, in a subset of cases, for fluorescence in situ hybridization.

\section{Immunohistochemistry}

Immunohistochemistry for HER2/neu was performed using CB11, a monoclonal antibody to the intracellular domain of the protein, and TAB250, a monoclonal antibody to the extracellular domain of the protein.

The immunohistochemical procedure was as follows: $4-\mu \mathrm{m}$ tissue sections were deparaffinized in two 5 -minute changes of xylene and rehydrated through alcohols to distilled water. Nonspecific reactivity was blocked with $3 \%$ hydrogen peroxide and $5 \%$ normal serum in phosphate buffered saline. The TAB250 antibody (Zymed, San Francisco, CA) was applied at a dilution of $1 / 150$ for 1 hour at room temperature after the sections were digested with the protease Ficin (Zymed) for $10-15$ minutes at $37^{\circ} \mathrm{C}$. The CB11 antibody (Novocastra, Newcastle upon Tyne, UK) was applied at 1:200 dilution for 1 hour at room temperature. Heat-induced epitope retrieval was not used before the application of CB11. After several washes in Tris buffered saline, sections were incubated for 30 minutes at room temperature with biotinylated goat anti-mouse immunoglobulin (Signet Labs Inc, Dedham, MA), followed by another 30-minute incubation with streptavidin-horseradish peroxidase (Signet). 3,3'-Diaminobenzidine (Sigma Chemicals, St. Louis, MO) was used as the chromogen, and the sections were counterstained with hematoxylin. Positive tissue controls for the HER2/neu antibodies were included in each run and consisted of sections of breast tumor known to overexpress HER2/neu protein and to show HER2/neu gene amplification as well as a cell line with known 3-fold amplification of the HER2/neu gene (SKBR3). Negative controls consisted of substituting Tris buffered saline for HER2/neu antibodies. Also, normal ductal epithelium acted as an internal negative control.

Only complete membrane staining of tumor cells was considered in the analysis of the results. The degree of immunohistochemical staining was assessed using the Allred semiquantitative scoring system $(1,15)$. Briefly, this scoring system is the sum of a proportion score and an intensity score. The proportion score is an estimate of the proportion of positive cells on the entire slide and is divided into the following categories: $0=$ no cells staining; $1=<1 \% ; 2=1-10 \% ; 3=11-33 \% ; 4=$ 


\begin{tabular}{|c|c|c|c|}
\hline Variable & $\begin{array}{l}\text { Ductal Carcinoma } \\
\text { In Situ }(n=91)\end{array}$ & $\begin{array}{c}\text { Invasive and In Situ } \\
\text { Carcinoma }(n=136)\end{array}$ & $\begin{array}{c}\text { Invasive Ductal } \\
\text { Carcinoma }(n=24)\end{array}$ \\
\hline \multicolumn{4}{|l|}{ Age $(y)$} \\
\hline$<50$ & 22 & 40 & 2 \\
\hline$\geq 50$ & 69 & 96 & 22 \\
\hline Range (mean) & 35-92 (58.3) & $31-88(58.1)$ & $41-92(66.7)$ \\
\hline \multicolumn{4}{|l|}{ Side } \\
\hline Left & 49 & 59 & 8 \\
\hline Right & 42 & 77 & 16 \\
\hline \multicolumn{4}{|l|}{ Procedure } \\
\hline Lumpectomy & 12 & 12 & 4 \\
\hline Lump + ax. & 5 & 50 & 12 \\
\hline Mastectomy & 4 & 4 & 1 \\
\hline Mast + ax. & 9 & 32 & 3 \\
\hline Wire local. & 60 & 13 & 0 \\
\hline Wire + ax. & 1 & 25 & 4 \\
\hline \multicolumn{4}{|c|}{ Ductal carcinoma in situ nuclear grade } \\
\hline 1 & $9(9.9)$ & $10(7.3)$ & - \\
\hline 2 & 47 (51.6) & $73(53.7)$ & - \\
\hline 3 & 35 (38.5) & $53(39.0)$ & - \\
\hline \multicolumn{4}{|l|}{ Carcinoma grade } \\
\hline Low & - & $32(23.5)$ & $4(16.7)$ \\
\hline Intermediate & - & 55 (40.4) & $11(45.8)$ \\
\hline High & - & $49(36.0)$ & $9(37.5)$ \\
\hline \multicolumn{4}{|l|}{ Nodal status } \\
\hline Negative & 14 & 69 & 9 \\
\hline Positive & 0 & 38 & 10 \\
\hline Unknown & 77 & 29 & 5 \\
\hline \multicolumn{4}{|l|}{ Estrogen receptor } \\
\hline Negative & - & 26 & 5 \\
\hline Positive & - & 103 & 19 \\
\hline Equivocal & - & 6 & 0 \\
\hline \multicolumn{4}{|l|}{ Progesterone receptor } \\
\hline Negative & - & 50 & 9 \\
\hline Positive & - & 76 & 13 \\
\hline Equivocal & - & 9 & 2 \\
\hline
\end{tabular}

${ }^{a}$ For each group, the number of patients $<$ and $\geq 50$ is given along with the age range and mean age at the time of surgery. Lump + ax, lumpectomy and axillary dissection; Mast + ax, mastectomy and axillary dissection; Wire local, wire localization biopsy; Wire + ax, wire localization biopsy and axillary dissection. There is no evidence of any difference in the distribution of ductal carcinoma in situ grade in the two groups (Wilcoxon Mann-Whitney test, $P=.75)$.

${ }^{\mathrm{b}}$ There is no evidence of any difference in the distribution of grade in the two groups (Wilcoxon Mann-Whitney test, $P=.63$ ).

$34-67 \% ; 5=>67 \%$. The intensity score estimates the average staining intensity of positive tumor cells: 0 = no staining, 1 = weak positive membrane staining, 2 = moderate, and 3 = strong staining. The two scores were added together to give a final numerical score ranging from 0 to 8. An immunohistochemical score of $\geq 5$ was considered positive for HER2/neu protein overexpression (16). The same scoring system was used to evaluate both invasive and in situ breast tumors. In the groups of invasive carcinomas with associated ductal carcinoma in situ, in situ and invasive components were scored independently of each other.

\section{Fluorescence In Situ Hybridization}

For fluorescence in situ hybridization, representative slides from 33 cases were hybridized using the PathVysion HER2/neu DNA probe kit from Vysis. The slides were deparaffinized in three washes of xylene and ethanol, then pretreated with $0.2 \mathrm{~N} \mathrm{HCl}$ and $1 \mathrm{~m} \mathrm{NaSCN}$. The slides were then enzyme digested using pepsin, denatured using $70 \%$ formamide at $73^{\circ} \mathrm{C}$, and hybridized overnight with a locus-specific probe for the HER2/neu gene and a chromosome 17 centromere enumeration probe. The following day, the slides were washed in posthybridization buffer and counterstained with DAPI. The slides were read on a fluorescent microscope (Leica DMBRX), and a minimum of 60 nuclei was counted per case. The HER2/neu probe (red signals) and chromosome 17 centromere enumeration probe (green signals) were recorded for each cell, and the average number of red and green signals per cell was calculated. The ratio of HER2/neu signals per cell to chromosome 17 centromeric signals per cell was then calculated. A HER2/CEP17 ratio of $\geq 2$ was considered positive for HER 2 / neu gene amplification (as per the manufacturer's recommendations). A HER2/CEP17 ratio of 0.8 to 1.8 was considered negative for HER2/neu gene amplification, whereas a ratio between 1.8 and 2 was considered indeterminate. 


\section{Statistical Analysis}

All statistical analysis was performed using exact nonparametric inference using StatXact 3 (CYTEL Software Corporation, Cambridge, MA, 1995). Fisher's exact test was used for all $2 \times 2$ inferences; the marginal homogeneity test was used for paired data; and otherwise, the Wilcoxon Mann-Whitney test, with stratification where indicated, was used for ordinal categories. In all cases, the exact mid- $P$ adjusted $P$ values were reported.

\section{RESULTS}

Of the 251 cases, 91 (36.2\%) were ductal carcinoma in situ, 24 (9.6\%) were pure invasive carcinomas, and $136(54.2 \%)$ were invasive carcinomas with associated in situ disease. The demographic information is summarized in Table 1 . The grade of the in situ and invasive disease in a case was concordant (e.g., Grade 3 ductal carcinoma in situ with high-grade invasive cancer) in 96/136 (70.6\%) of cases. The majority of the discordant cases were low-grade cancers with associated nuclear Grade 2 ductal carcinoma in situ.

The results of the immunohistochemical studies for CB11 are given in Table 2. As stated previously, a final immunohistochemical score of $\geq 5$ was considered positive for HER 2 /neu protein overexpression. The majority of cases with immunohistochemical scores of $<5$ showed no complete membrane staining with the CB11 antibody and were scored as 0 . A few cases showed weak or focal

TABLE 2. Incidence of HER2/neu Protein Overexpression

\begin{tabular}{cc}
\hline \multicolumn{1}{c}{ Group } & CB11 $\geq 5, \%(n)$ \\
\hline Ductal Carcinoma in situ & $34.1(31 / 91)$ \\
Invasive and in situ carcinoma & $16.9(23 / 136)$ \\
Invasive component & $23.5(32 / 136)$ \\
In situ component & $12.5(3 / 24)$ \\
Invasive ductal carcinoma & \\
\hline
\end{tabular}

A combined immunohistochemical score of $\geq 5$ was considered positive for protein overexpression. Difference between HER2/neu incidence in ductal carcinoma in situ and invasive carcinoma (with and without associated in situ disease) was statistically significant $(P=.018)$. complete membrane staining with CB11, giving a final immunohistochemical score of 3 or 4 . Overall, there was good concordance in the results obtained with the two antibodies, with concordance between CB11 and TAB250 of 96\% (154/160) and 92\% (209/ 227 ) for the invasive tumors and ductal carcinoma in situ, respectively. There was weak evidence $(P=$ .09) that the concordance was lower in ductal carcinoma in situ. Subsequent results are for CB11 only, although there were no substantive differences between CB11 and TAB250. In the group of invasive carcinomas with associated ductal carcinoma in situ, there was concordance in the immunohistochemical classification between the invasive and in situ components in 123/136 (90.4\%) of cases. Discordant cases were mostly $(11 / 13)$ cases that were positive for HER2/neu overexpression in the in situ component but not in the invasive tumor. The majority of these cases showed immunohistochemical scores around the cut point (i.e., 3-5). However, one case (Case 21) showed no staining in the invasive component (score of 0 ), whereas the ductal carcinoma in situ component had a score of 5. Comparing the three groups (pure ductal carcinoma in situ, ductal carcinomas with associated in situ disease, and pure invasive ductal carcinomas), there was evidence of a difference in the incidence of HER $2 /$ neu protein overexpression ( $P=.018$, using the Wilcoxon-Mann-Whitney Test, which uses the ordering implicit in the three groups). When controlling for possible confounding by tumor grade (using the stratified Wilcoxon-Mann-Whitney test, $P=.011$ ), the trend in HER2/neu overexpression between the three groups remained.

The rate of HER2/neu overexpression in different tumor grades is shown in Table 3 . There was an increased incidence of HER2/neu protein overexpression with increasing tumor grade. This progression was highly significant (see Table 3 ) in cases of pure ductal carcinoma in situ and in cases of invasive carcinomas with associated in situ disease. Although not statistically significant in cases of pure invasive ductal carcinoma, the trend was consistent with the other groups. The trend in HER2/neu protein overexpres-

TABLE 3. Incidence of HER2/neu Protein Overexpression (Determined by CB11 Immunohistochemistry), by Tumor Grade

\begin{tabular}{|c|c|c|c|c|}
\hline \multirow{2}{*}{ Tumor Group } & \multicolumn{3}{|c|}{ Tumor Grade, \% $(n)$} & \multirow{2}{*}{ Test of Trend in Grade } \\
\hline & Low & Intermediate & High & \\
\hline Ductal carcinoma in situ $(n=91)$ & $0(0 / 9)$ & $21.3(10 / 47)$ & $60.0(21 / 35)$ & $P<.0001$ \\
\hline \multicolumn{5}{|l|}{ Invasive and in situ carcinoma ( $n=136)$} \\
\hline Invasive & $0(0 / 32)$ & $16.4(9 / 55)$ & $28.6(14 / 49)$ & $P=.0007$ \\
\hline In situ & $10(1 / 10)$ & $13.7(10 / 73)$ & $39.6(21 / 53)$ & $P=.0004$ \\
\hline Invasive ductal carcinoma $(n=24)$ & $0(0 / 4)$ & $9.1(1 / 11)$ & $22.2(2 / 9)$ & $P=.21$ \\
\hline Test of trend between groups & $\mathrm{P}=.57$ & $\mathrm{P}=.19$ & $\mathrm{P}=.016^{*}$ & \\
\hline
\end{tabular}

* Statistically significant.

Number and percent of cases positive for HER2/neu protein overexpression as determined by the antibody CB11, arranged by tumor grade. Difference in HER2/neu incidence between high grade ductal carcinoma in-situ and high grade invasive carcinoma (with and without associated in-situ disease) was statistically significant $(\mathrm{p}=0.016)$. 
TABLE 4. Incidence of HER/neu Protein Overexpression (Determined by CB11 Immunohistochemistry), by Prognostic Factors

\begin{tabular}{|c|c|c|c|c|c|}
\hline \multirow[t]{2}{*}{ Prognostic Factor } & \multicolumn{2}{|c|}{$\begin{array}{l}\text { Ductal Carcinoma In } \\
\quad \text { Situ }(n=91)\end{array}$} & \multicolumn{2}{|c|}{$\begin{array}{l}\text { Invasive and In Situ } \\
\text { Carcinoma }(n=136)\end{array}$} & \multirow{2}{*}{$\begin{array}{l}\text { Invasive Ductal Carcinoma, \% } \\
\qquad(n ; n=24)\end{array}$} \\
\hline & $\%(\mathrm{n})$ & $\mathrm{P}$ & $\%(\mathrm{n})$ & $\mathrm{P}$ & \\
\hline \multicolumn{6}{|l|}{ Age $(y)$} \\
\hline$<50$ & $27.3(6 / 22)$ & & $30.0(12 / 40)$ & & $0.0(0 / 2)$ \\
\hline$>=50$ & $36.2(25 / 69)$ & .73 & $11.5(11 / 96)$ & .015 & $13.6(3 / 22)$ \\
\hline \multicolumn{6}{|l|}{ Nodal status } \\
\hline Negative & N/A & & $15.9(11 / 69)$ & & $0.0(0 / 9)$ \\
\hline Positive & N/A & & $23.7(9 / 38)$ & & $20.0(2 / 10)$ \\
\hline Unknown & N/A & & $10.3(3 / 29)$ & .43 & $20.0(1 / 5)$ \\
\hline \multicolumn{6}{|l|}{ Estrogen receptor } \\
\hline Negative & N/A & & $42.3(11 / 26)$ & & $20.0(1 / 5)$ \\
\hline Positive & N/A & & $10.7(11 / 103)$ & & $10.5(2 / 19)$ \\
\hline Equivocal & N/A & & $16.7(1 / 6)$ & .001 & $0.0(0 / 0)$ \\
\hline \multicolumn{6}{|l|}{ Progesterone receptor } \\
\hline Negative & N/A & & $30.0(15 / 50)$ & & $22.2(2.9)$ \\
\hline Positive & N/A & & $9.2(7 / 76)$ & & $7.7(1 / 13)$ \\
\hline Equivocal & N/A & & $11.1(1 / 9)$ & .004 & $0.0(0 / 2)$ \\
\hline \multicolumn{6}{|c|}{ Extensive intraductal component } \\
\hline Negative & N/A & & $12.4(13 / 105)$ & & N/A \\
\hline Positive & N/A & & $32.3(10 / 31)$ & .007 & N/A \\
\hline
\end{tabular}

$P$ values given refer to the statistical significance of the difference in proportions, ignoring unknown and equivocal groups.

Incidence of positive HER2/neu protein overexpression as determined by immunohistochemistry (CB11) correlated with different prognostic factors. $\mathrm{P}$-values given refer to the statistical significance of the difference in proportions (ignoring unknown and equivocal groups).

sion among the three groups was statistically significant only in the high-grade tumors, although a consistent (but smaller in magnitude) trend was apparent in the intermediate grade tumors.

The rate of HER2/neu overexpression was statistically significantly correlated with age, lack of estrogen and progesterone receptors, and presence of an extensive intraductal component (EIC). Tumors were categorized as EIC positive if the ductal carcinoma in situ comprised a substantial $(\geq 25 \%$ ) portion of the tumor mass and was also present at the periphery of the invasive carcinoma or if the tumor was predominantly in situ with multiple small foci of invasive carcinoma (17). These results are shown in Table 4. In addition, there was statistical evidence that the relationship between age and HER2/neu status differed between the pure ductal carcinoma in situ group and the group of tumors with both invasive and in situ components $(P=.037$ using Zelen's test for the homogeneity of odds ratio). Statistical analysis was not carried out on the group of pure invasive carcinomas because of the small sample size.

Fluorescence in situ hybridization was performed on 33 cases. The cases chosen included cases of pure ductal carcinoma in situ, pure invasive ductal carcinoma, and cases of ductal carcinoma with associated in situ disease. Thirteen of the cases were positive for HER2/neu protein overexpression by immunohistochemistry, 11 were negative by immunohistochemistry, and the remainder were cases in which weak staining was seen using the CB11 antibody (immunohistochemical score 3-4). Also, cases in which there was a difference between the immunohistochemical score obtained in the invasive carcinoma and the associated ductal carcinoma in situ were evaluated by
TABLE 5. Comparison of Immunohistochemistry and Fluorescence In Situ Hybridization Results in Discordant Cases

\begin{tabular}{rccc}
\hline $\begin{array}{c}\text { Case } \\
\text { No. }\end{array}$ & $\begin{array}{c}\text { CB11 } \\
\text { Score } \\
\text { (Invasive) }\end{array}$ & $\begin{array}{c}\text { HER2/CEP17 } \\
\text { (Invasive) }\end{array}$ & $\begin{array}{c}\text { HER2/CEP17 } \\
\text { (In Situ })\end{array}$ \\
\hline 5 & 0 & 2.29 & 2.36 \\
11 & 3 & 3.69 & 2.91 \\
13 & 3 & 2.80 & 2.97 \\
21 & 0 & 1.14 & 6.50 \\
\hline
\end{tabular}

Cases 5, 11, and 13 showed discordant results between immunohistochemistry and FISH, whereas Case 21 showed discordance between the HER2/neu gene amplification status in the in situ and invasive components.

fluorescence in situ hybridization, including Case 21, in which the invasive tumor showed negative staining (score of 0) and the in situ component was positive (score of 5). Complete concordance was seen between HER2/neu protein overexpression and gene amplification in 30 of 33 cases (91\%). The three discordant cases (Cases 5, 11, and 13) showed low-level HER2/neu gene amplification by fluorescence in situ hybridization in the absence of protein overexpression, as assessed by CB11 (Table 5). In invasive tumors with associated in situ disease, there was complete concordance between the in situ and invasive components in all but one case analyzed by fluorescence in situ hybridization. In this case (Case 21), there was unequivocal gene amplification in the in situ component (HER2/CEP17 = 6.5) (Fig. 1); whereas gene amplification was not seen in the invasive component $($ HER2/CEP17 = 1.14). As discussed above, this case had shown a marked discordance in HER2/ neu staining between the invasive and in situ components of the tumor by immunohistochemistry. 


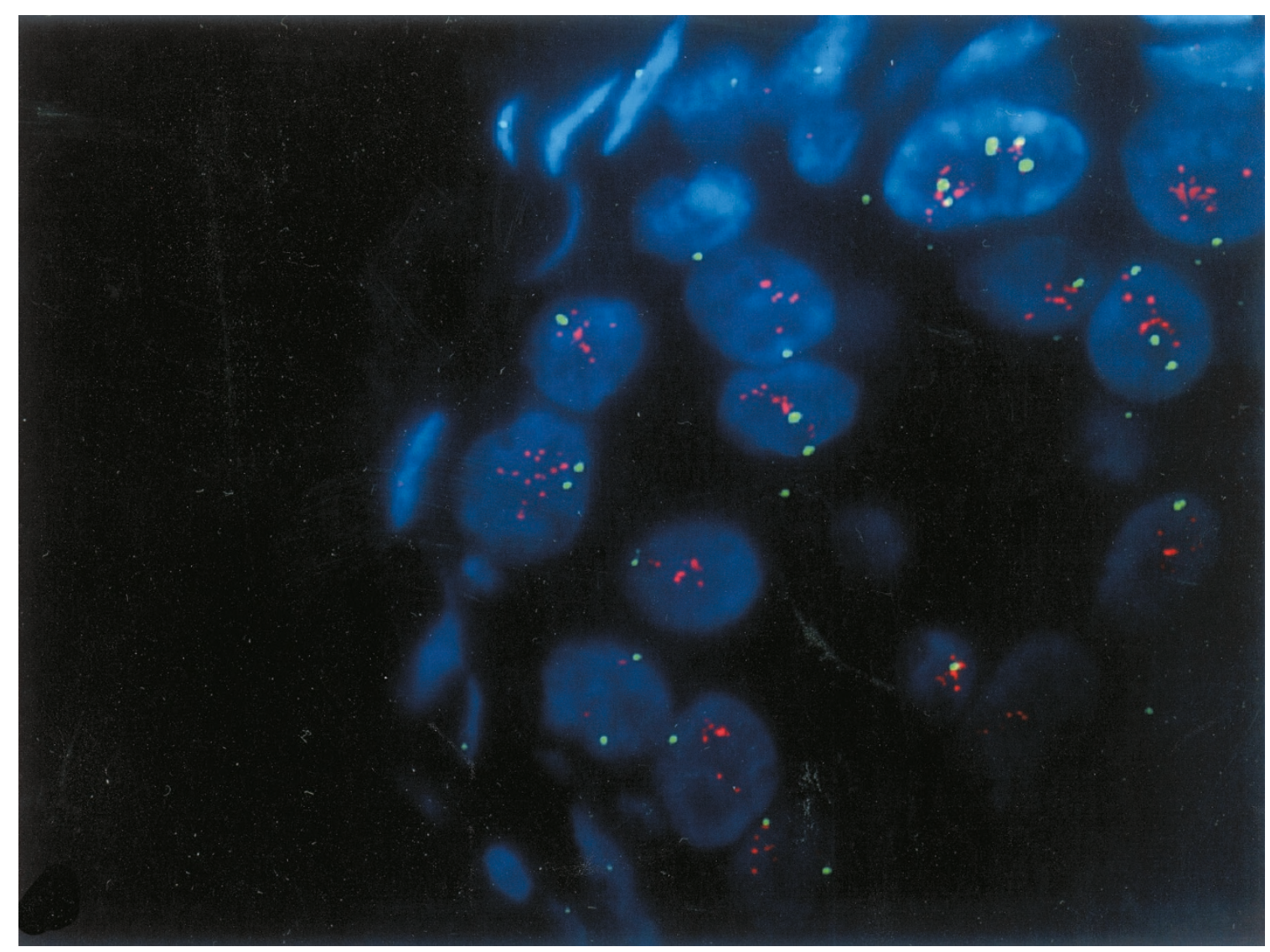

FIGURE 1. Fluorescent in situ hybridization of Case 21 showing HER2/neu gene amplification in the in situ component; HER2/CEP17 ratio $=6.50$.

\section{DISCUSSION}

The clinical significance of HER2/neu overexpression/amplification in invasive breast cancer is considerable and compelling. The initial study by Slamon et al. in 1987 (9) found a 30\% incidence of HER2/neu overexpression/amplification in women with lymph node-positive breast cancer, and this was associated with a significantly poorer outcome, increased risk of recurrent disease, and shorter overall survival. Subsequent studies have confirmed these results $(18,19)$, with some studies reporting $\leq 35 \%$ difference in survival at 4 years for lymph node-positive patients with and without HER2/neu overexpression/amplification. The prognostic role of HER2/neu in lymph node-negative breast cancer has been controversial $(5,7,20-24)$. However, a recent meta-analysis indicates that HER2/neu does have a pure prognostic effect, although the magnitude of this negative prognostic effect is weak to moderate (25). In addition to its prognostic role, HER2/neu may predict response to therapy in patients with breast carcinoma. Overexpression/amplification of HER2/neu has been shown to be associated with an increased sensitivity to doxorubicin-based therapies $(3,4,6)$.

Although HER2/neu overexpression has important clinical significance in invasive breast cancer, its incidence in invasive disease is lower than its incidence in ductal carcinoma in situ. In this retrospective study, HER2/neu overexpression was seen in $\leq 35 \%$ of cases of ductal carcinoma in situ overall but in $60 \%$ of high-grade ductal carcinoma in situ. However, the rate of HER2/neu overexpression was only $12-17 \%$ in the invasive ductal carcinomas (with and without associated ductal carcinoma in situ) overall, with an incidence of only $29 \%$ in the high-grade invasive carcinomas, Table 3.

The high incidence of HER2/neu overexpression in ductal carcinoma in situ would suggest that this oncogene has an important role to play in in situ disease. HER2/neu overexpression/amplification in ductal carcinoma in situ may lead to increased cell proliferation, increased cell motility with dissemination along the basement membrane, and increased burden of disease (26). HER2/neu overexpression/amplification does not, however, appear to be a prerequisite in the progression of ductal carcinoma in situ to invasive disease, as suggested by this study and others $(13,27,28)$. The finding in this study of definitive evidence of gene amplification in the in situ component (HER2/CEP17 = 6.5) and yet a normal HER2/CEP17 ratio in the adjacent invasive tumor $($ HER2/CEP17 $=1.14)$ suggests that the invasive component arose from a clone of tu- 
mor cells that developed invasive capabilities, in the absence of HER2/neu gene amplification. A recent study (29) assessing HER2/neu overexpression in ductal carcinoma in situ and invasive disease obtained similar results and concluded that HER2/ neu overexpression did not appear to be involved in the invasive process. The authors speculated that given the high incidence of HER2/neu alterations in high-grade ductal carcinoma in situ associated with comedo necrosis, these alterations may confer a growth advantage to ductal carcinoma in situ under ischemic conditions. However, once invasion occurs, the associated neovascularization would relieve the ischemic conditions, thus allowing the possible clonal expansion of neoplastic cells lacking HER2/neu alterations, as such cells would not require resistance to ischemia. This hypothesis is supported by the demonstration of strong tumor cell expression of the angiogenic factor vascular permeability factor/vascular endothelial growth factor and strong endothelial cell expression of their receptors in the stroma surrounding both ductal carcinoma in situ and invasive ductal carcinoma (30). Thus, when ductal carcinoma in situ progresses to invasion, the neoplastic cells appear to invade a highly vascular stroma. Indeed this stromal change may be a prerequisite to the invasive process.

Representative cases were examined by fluorescence in situ hybridization for evidence of HER2/ neu gene amplification. Although more technically complex to perform, and more expensive, fluorescence in situ hybridization has the advantage of being able to identify gene amplification in individual cells while retaining the morphologic appearance of the tissue. It has been previously reported that HER2/neu protein overexpression is almost always due to HER2/neu gene amplification (8, 31, 32). In our study, three tumors demonstrated gene amplification in the absence of detectable protein overexpression. In two of these cases, the level of gene amplification was very low (HER2/CEP17 = 2.3 and 2.8, respectively) and was only slightly higher in the third case. It is likely that the degree of amplification in these cases resulted in an increase in protein overexpression that was too low to be detectable by the antibodies used.

Although there is a high incidence of HER2/neu overexpression/amplification in ductal carcinoma in situ, studies have shown that benign proliferative breast lesions and atypical hyperplasias do not generally show any overexpression/amplification of HER2/neu (13). In this study, some cases had areas of atypical ductal hyperplasia adjacent to the invasive carcinomas and ductal carcinoma in situ, and there was no positive staining in the atypical ductal hyperplasia using either CB11 or TAB250. We also tested a small number of cases of pure atypical ductal hyperplasia, and no HER2/neu positivity was seen using either antibody.

In conclusion, HER2/neu alterations are undoubtedly important in ductal carcinoma in situ and are usually maintained in an adjacent invasive ductal carcinoma. However, the lower overall incidence of HER2/neu gene amplification/protein overexpression in invasive carcinomas (with and without associated ductal carcinoma in situ) and the rare occurrence of HER2/neu gene amplification in in situ disease, but not in the adjacent invasive tumor, suggest that it may not be a prerequisite in the progression of ductal carcinoma in situ to invasive cancer. Other events, such as the development of a vascular stroma adjacent to the areas of in situ disease, may be more critical in the progression to invasion.

\section{REFERENCES}

1. Allred DC, Clark GM, Elledge R, et al. Association of p53 protein expression with tumor cell proliferation rate and clinical outcome in node-negative breast cancer. J Natl Cancer Inst 1993;85:200-6.

2. Muss HB, Thor AD, Berry DA, et al. c-erbB-2 expression and response to adjuvant therapy in women with node-positive early breast cancer [published erratum appears in N Engl J Med 1994 Jul 21;331 (3):211]. N Engl J Med 1994;330: 1260-6.

3. Thor AD, Berry DA, Budman DR, et al. erbB-2, p53, and efficacy of adjuvant therapy in lymph node-positive breast cancer. J Natl Cancer Inst 1998;90:1346-60.

4. Paik S, Bryant J, Park C, et al. erbB-2 and response to doxorubicin in patients with axillary lymph node- positive, hormone receptor-negative breast cancer. J Natl Cancer Inst 1998;90:1361-70.

5. Andrulis IL, Bull SB, Blackstein ME, et al. neu/erbB-2 amplification identifies a poor-prognosis group of women with node-negative breast cancer. Toronto Breast Cancer Study Group. J Clin Oncol 1998;16:1340-9.

6. Paik S, Bryant J, Tan-Chiu E, et al. HER2/neu and choice of adjuvant chemotherapy for invasive breast cancer: national surgical adjuvant breast and bowel project protocol b-15. J Natl Cancer Inst 2000;92:1991-8.

7. Press MF, Bernstein L, Thomas PA, et al. HER-2/neu gene amplification characterized by fluorescence in situ hybridization: poor prognosis in node-negative breast carcinomas. J Clin Oncol 1997;15:2894-904.

8. Slamon DJ, Godolphin W, Jones LA, et al. Studies of the HER-2/neu proto-oncogene in human breast and ovarian cancer. Science 1989;244:707-12.

9. Slamon DJ, Clark GM, Wong SG, et al. Human breast cancer: correlation of relapse and survival with amplification of the HER-2/neu oncogene. Science 1987;235:177-82.

10. van de Vijver MJ, Peterse JL, Mooi WJ, et al. Neu-protein overexpression in breast cancer. Association with comedotype ductal carcinoma in situ and limited prognostic value in stage II breast cancer. N Engl J Med 1988;319:1239-45.

11. Lodato RF, Maguire HCJ, Greene MI, Weiner DB, LiVolsi VA. Immunohistochemical evaluation of c-erbB-2 oncogene expression in ductal carcinoma in situ and atypical ductal hyperplasia of the breast. Mod Pathol 1990;3:449-54.

12. Bartkova J, Barnes DM, Millis RR, Gullick WJ. Immunohistochemical demonstration of c-erbB-2 protein in mammary ductal carcinoma in situ. Hum Pathol 1990;21:1164-7. 
13. Allred DC, Clark GM, Molina R, et al. Overexpression of HER-2/neu and its relationship with other prognostic factors change during the progression of in situ to invasive breast cancer. Hum Pathol 1992;23:974-9.

14. Elston CW, Ellis IO. Pathological prognostic factors in breast cancer. I. The value of histological grade in breast cancer: experience from a large study with long-term follow-up. Histopathology 1991;19:403-10.

15. Allred DC, Harvey JM, Berardo M, Clark GM. Prognostic and predictive factors in breast cancer by immunohistochemical analysis. Mod Pathol 1998;11:155-68.

16. O'Malley FP, Parkes R, Latta E, et al. Comparison of HER2/ $\mathrm{NEU} /$ neu status assessed by quantitative polymerase chain reaction and immunohistochemistry. Am J Clin Pathol 2001; 115:504-11.

17. Schnitt JF, Connolly JL, Harris JR, Hellman S, Cohen RB. Pathologic predictors of early local recurrence in stage I and II breast cancer treated by primary radiation therapy. Cancer 1984;53:1049-57.

18. Borg A, Tandon AK, Sigurdsson H, et al. HER-2/neu amplification predicts poor survival in node-positive breast cancer. Cancer Res 1990;50:4332-7.

19. Wright C, Angus B, Nicholson S, et al. Expression of c-erbB-2 oncoprotein: a prognostic indicator in human breast cancer. Cancer Res 1989;49:2087-90.

20. Gusterson BA, Machin LG, Gullick WJ, et al. c-erbB-2 expression in benign and malignant breast disease. $\mathrm{Br} \mathrm{J}$ Cancer 1988;58:453-7.

21. Gullick WJ, Love SB, Wright C, et al. c-erbB-2 protein overexpression in breast cancer is a risk factor in patients with involved and uninvolved lymph nodes. Br J Cancer 1991;63: $434-8$.

22. Rilke F, Colnaghi MI, Cascinelli N, et al. Prognostic significance of HER-2/neu expression in breast cancer and its relationship to other prognostic factors. Int J Cancer 1991; 49:44-9.
23. Allred DC, Clark GM, Tandon AK, et al. HER-2/neu in nodenegative breast cancer: prognostic significance of overexpression influenced by the presence of in situ carcinoma. J Clin Oncol 1992;10:599-605.

24. Ro JS, el-Naggar A, Ro JY, et al. c-erbB-2 amplification in node-negative human breast cancer. Cancer Res 1989;49: 6941-4.

25. Yamauchi H, Stearns V, Hayes DF. When is a tumor marker ready for prime time? A case study of c-erbB-2 as a predictive factor in breast cancer. J Clin Oncol 2001;19:2334-56.

26. De PC, Schelfhout AM. The neu-protein and breast cancer. Virchows Arch 1995;426:107-15.

27. Anderson TJ. c-erbB-2 oncogene in breast cancer: the right target or a decoy? [editorial]. Hum Pathol 1992;23:971-3.

28. Barnes DM, Bartkova J, Camplejohn RS, et al. Overexpression of the c-erbB-2 oncoprotein: why does this occur more frequently in ductal carcinoma in situ than in invasive mammary carcinoma and is this of prognostic significance? Eur J Cancer 1992;28:644-8.

29. Tsuda H, Hirohashi S. Multiple developmental pathways of highly aggressive breast cancers disclosed by comparison of histological grades and c-erbB-2 expression patterns in both the non-invasive and invasive portions. Pathol Int 1998;48: 518-25.

30. Brown LF, Guidi AJ, Schnitt SJ, et al. Vascular stroma formation in carcinoma in situ, invasive carcinoma, and metastatic carcinoma of the breast. Clin Cancer Res 1999;5:104156.

31. Tubbs RR, Pettay JD, Roche PC, et al. Discrepancies in clinical laboratory testing of eligibility for trastuzumab therapy: apparent immunohistochemical false-positives do not get the message. J Clin Oncol 2001;19:2714-21.

32. Pauletti G, Godolphin W, Press MF, Slamon DJ. Detection and quantitation of HER-2/neu gene amplification in human breast cancer archival material using fluorescence in situ hybridization. Oncogene 1996;13:63-72. 